\title{
Estado da arte da produção científica dos congressos brasileiros em Etnomatemática
}

\author{
Milton Rosa ${ }^{1}$ \\ Daniel Clark Orey²
}

\begin{abstract}
RESUMO
O principal objetivo desse artigo teórico é identificar por meio da análise dos trabalhos publicados nos anais dos cinco Congressos Brasileiros de Etnomatemática (CBEm), quais as dimensões desse Programa foram utilizadas na condução de investigações nesse campo de pesquisa. Nesse estudo do tipo estado da arte, foram analisados 463 resumos de trabalhos publicados nos anais dessas edições dos CBEm. Uma pluralidade de concepções teóricas, metodológicas e pedagógicas refletiu-se nas seis dimensões do Programa Etnomatemática, que foram utilizadas para o desenvolvimento desse estado da arte. Concluímos que a Etnomatemática assume um compromisso importante nas questões do ensino e aprendizagem em matemática, bem como as dimensões que emergiram nos trabalhos analisados sugerem caminhos promissores para uma inserção da perspectiva desse Programa na Educação Matemática, principalmente, com relação à sua ação pedagógica no currículo matemático por meio de sua dimensão educacional.
\end{abstract}

PALAVRAS-CHAVE: Congresso Brasileiro de Etnomatemática. Estado da Arte. Etnomatemática. Produção Científica. Seis Dimensões.

The State of the Art of Scientific Production Shared in Brazilian

Ethnomathematics Congresses

\begin{abstract}
The main objective of this theoretical article is to identify through analysis of the annals of five Brazilian National Ethnomathematics Congresses (CBEm). The dimensions of the Ethnomathematics Program
\end{abstract}

1 Doutorado em Educação em Liderança Educacional. Universidade Federal de Ouro Preto, Ouro Preto, Minas Gerais, Brasil. E-mail: Milton.rosa@ufop.edu.br.

2 Doutor em Educação em Currículo e Instrução. Universidade Federal de Ouro Preto, Ouro Preto, Minas Gerais, Brasil. E-mail: oreydc@mail.com. 
were investigated in this research field. This study deals with the state of the art research type in which 463 abstracts of papers presented in the annals of the editions of CBEm. The plurality of the theoretical, methodological, and pedagogical concepts was reflected in six dimensions of the Ethnomathematics Program that were used in the development of this state of art. We conclude that ethnomathematics continues to assume an important commitment to questions of teaching and learning mathematics. As well, the dimensions that emerged from the analyzed papers suggest a promising path for the insertion of this perspective in mathematics education, especially, in regard to its pedagogical action into mathematics curriculum through its educational dimension.

KEYWORDS: Brazilian Ethnomathematics Congresses. State of the Art. Ethnomathematics. Scientific Production. Six Dimensions.

\section{Considerações iniciais}

A Etnomatemática como um Programa de pesquisa emergiu com a palestra de abertura do educador e filósofo brasileiro Ubiratan D'Ambrosio no Quinto Congresso Internacional de Educação Matemática (ICME-5) em Adelaide, Austrália, em 1984, para problematizar as relações entre a matemática, a cultura e a sociedade.

Atualmente, esse Programa reune matemáticos, investigadores e educadores que têm diferentes motivações para buscar uma compreensão da Etnomatemática com o auxílio de diversas organizações e grupos de estudos nacionais e internacionais, como, por exemplo, o Grupo de Estudo Internacional da Etnomatemática (ISGEm), o Grupo de Trabalho sobre o Papel da Etnomatemática na Educação Matemática (TSG35), do Congresso Internacional de Educação Matemática (ICME), a Red Latinoamericana de Etnomatemática e o Grupo de Estudos e Pesquisas em Etnomatemática (GEPEm), da Faculdade da Educação, da Universidade de São Paulo.

Desde 1984, seis Conferências Internacionais em Etnomatemática (ICEm) foram realizadas: a primeira na Espanha (1998), a segunda no 
Brazil (2002), a terceira na Nova Zelândia (2006), a quarta nos Estados Unidos (2010), a quinta em Moçambique (2014) e a sexta na Colômbia (2018). A Sétima Conferência Internacional em Etnomatemática será realizada em Papua-Nova Guiné, em 2022. É importante ressaltar que essas conferências internacionais têm atraído etnomatemáticos, pesquisadores e educadores de, aproximadamente, 50 países, ilustrando o crescimento internacional de investigações e estudos em Etnomatemática.

Ressaltamos que, internacionalmente, o Brasil se mantém como líder na condução de investigações em Etnomatemática, sendo o único país que realizou cinco congressos nacionais relacionados com esse Programa. Por exemplo, o Sexto Congresso Brasileiro de Etnomatemática será realizado na Universidade Federal de Tocantins (UFT), no campus de Palmas, em Tocantins, em outubro de 2020.

Nesse contexto, o principal objetivo desse artigo teórico é identificar por meio da análise dos trabalhos publicados nos anais dos cinco Congressos Brasileiros de Etnomatemática (CBEm), quais são as dimensões da Etnomatemática que foram utilizadas na condução de pesquisas relacionadas com esse Programa.

\section{Um breve histórico dos CBEm}

O Primeiro Congresso Brasileiro de Etnomatemática (CBEm1) foi realizado no período de 01 a 04 de novembro de 2000, na Faculdade de Educação, da Universidade de São Paulo (USP), em São Paulo (SP), com, aproximadamente, 300 participantes. Os principais objetivos desse congresso foram: a) reconhecer o potencial das diferenças culturais no processo de ensino e aprendizagem em matemática, b) compartilhar os resultados de pesquisas e a análise das raízes culturais das ideias matemáticas, c) compartilhar os modos de recuperar/investigar como os outros compreendem a matemática e d) discutir as bases teóricas da Etnomatemática. 
O Segundo Congresso Brasileiro de Etnomatemática (CBEm2) foi realizado no período de 04 a 07 de abril de 2004, na Universidade Federal do Rio Grande do Norte (UFRN), em Natal (RN), com 179 participantes. De acordo com a organização desse evento, o "CBEm2 constituiu-se em mais um passo na consolidação da Etnomatemática como área do conhecimento" (MOREY, 2004, p. 7), que visava fortalecer esse Programa como uma tendência de pesquisas e estudos em Educação Matemática.

O Terceiro Congresso Brasileiro de Etnomatemática (CBEm3) foi realizado no período de 26 a 29 de março de 2008, na Faculdade de Educação, da Universidade Federal Fluminense (UFF), em Niterói (RJ), com, aproximadamente, 300 participantes. O tema desse congresso foi Etnomatemática: novos desafios teóricos e pedagógicos, sendo que o seu principal objetivo foi promover um amplo debate sobre os problemas de pesquisa no âmbito da Etnomatemática em termos nacional e internacional, bem como estabelecer quais são as perspectivas inovadoras diante das demandas de ensino dos diferentes grupos culturais e nas consequentes necessidades de formação de professores.

O Quarto Congresso Brasileiro de Etnomatemática (CBEm4) foi realizado no período de 13 a 17 de novembro de 2012, em Belém (PA), na Universidade Federal do Pará (UFPA), com, aproximadamente, 400 participantes. Esse congresso envolveu professores e pesquisadores de educação matemática e demais áreas de interesse, de diferentes regiões do Brasil e, também, do exterior. O tema desse congresso foi Cultura, Educação Matemática e Escola, que também promoveu um amplo debate sobre as investigações em Etnomatemática e a sua relação com o processo de ensino e aprendizagem em matemática e a formação de professores.

O Quinto Congresso Brasileiro de Etnomatemática (CBEm5) foi realizado no período de 11 a 14 de setembro de 2016, na Universidade Federal de Goiás (UFG), em Goiânia (GO), com, aproximadamente, 650 participantes. Esse congresso teve como tema Etnomatemática, encontro de saberes e uma nova universidade, que promoveu a aproximação das 
demandas de responsabilidades humanas, sociais, culturais e educacionais da contemporaneidade com a Etnomatemática. Assim, o CBEm5 procurou aglutinar as diferentes pesquisas desenvolvidas pela área no Brasil, sistematizar os seus avanços e progressos, bem como discutir as suas preocupações, os seus desafios, insurgências e complexidades diante do contexto do constante movimento etnomatemático.

É importante ressaltar que as cinco edições do Congresso Brasileiro de Etnomatemática (CBEm) confirmam e consolidam o desenvolvimento das relações entre os investigadores e educadores etnomatemáticos no âmbito nacional e internacional.

\section{Seis dimensões do Programa Etnomatemática}

Para que possamos entender e compreender o enfoque holístico do Programa Etnomatemática, é importante desencadearmos uma breve discussão sobre as suas seis dimensões, que são denominadas de Histórica, Cognitiva, Política, Educacional, Conceitual e Epistemológica. A figura 1 mostra as seis dimensões desse Programa.

FIGURA 1: Seis dimensões do Programa Etnomatemática

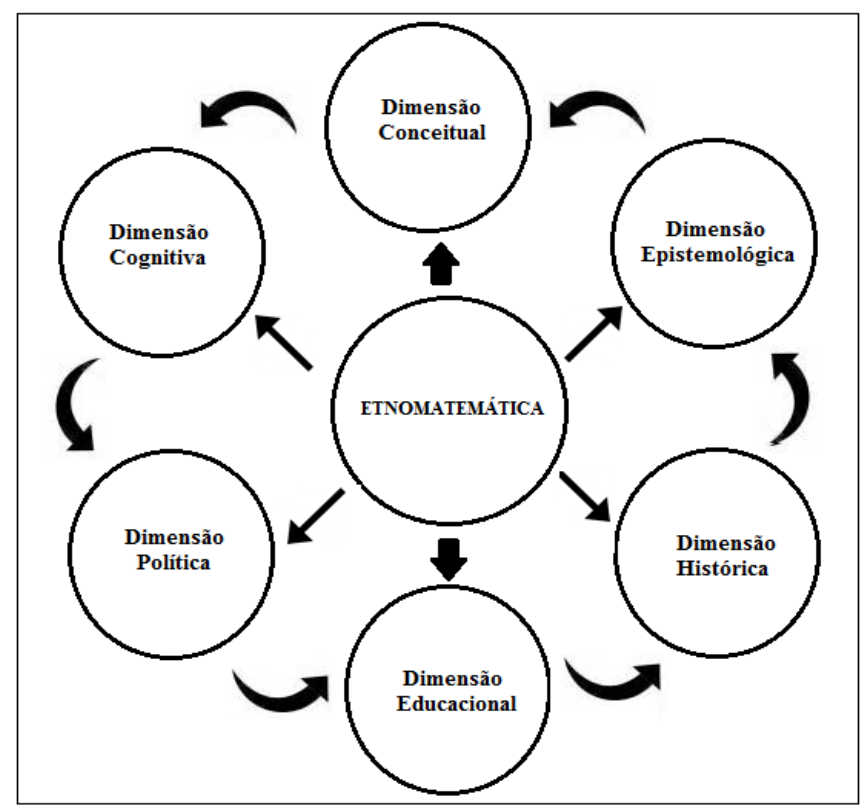

Fonte: Adaptado de Alves (2014) 


\section{Dimensão histórica}

Para que se possa alcançar o objetivo de verificar o elo entre as tradições e a modernidade, surgem questões sobre as quais os conteúdos matemáticos devem ser ensinados para os alunos, principalmente, àqueles pertencentes aos grupos minoritários e às classes dominadas.

Porém, "essas questões somente podem ser formuladas e respondidas em um contexto histórico, procurando entender a evolução dos sistemas culturais na história da humanidade" (D'AMBROSIO, 2009, p. 76). Desse modo, a Etnomatemática é um Programa de pesquisa em história e filosofia da Matemática, que propõe a relação do currículo matemático com o:

(...) reexame histórico e epistemológico do próprio conhecimento científico, e ao mesmo tempo [com] uma reconstrução histórica dos momentos da construção desse mesmo conhecimento. (...) A recuperação e, mesmo, a reconstrução dessas idéias, o que na verdade significaria fazer a história das ideias perdedoras, é a primeira tarefa do nosso Programa (D’AMBROSIO, 1998, p. 45).

Corroborando com essa asserção, é importante a compreensão de que a história da matemática é sempre escrita conforme o ponto de vista vitorioso, carecendo da dimensão social que pode esclarecer a natureza do conhecimento matemático (D’AMBROSIO, 1998).

De acordo com Rosa (2010), essa dimensão propõe que o conhecimento matemático seja construido a partir das interpretações históricas dos conhecimentos desenvolvidos pelos membros de grupos culturais distintos de acordo com as origens do conhecimento matemático e com as dificuldades enfrentadas no cotidiano. 


\section{Dimensão cognitiva}

Nessa dimensão concentram-se as manifestações matemáticas presentes no pensamento dos membros de culturas distintas de acordo com a aquisição, acumulação e difusão do conhecimento matemático, no decorrer da história, através das gerações. Assim, as ideias matemáticas, como, por exemplo, comparar, classificar, quantificar, medir, explicar, generalizar, modelar e avaliar, podem ser mais bem compreendidas como fenômenos sociais, culturais e antropológicos que desencadeiam o desenvolvimento de sistemas de conhecimentos relacionados com os fazeres e saberes dos membros de um determinado grupo cultural.

Nesse direcionamento, D’Ambrosio (2009) ressalta que não se podem avaliar as habilidades cognitivas dos membros desses grupos de modo externo ao seu contexto cultural. Essa dimensão considera e valoriza as manifestações matemáticas presentes na estrutura cognitiva dos alunos, pois as questões social, cultural, econômica, ambiental e política são elementos básicos para o desenvolvimento de estudos sobre o conhecimento e o comportamento desenvolvidos pela humanidade.

De acordo com essa dimensão, o Programa Etnomatemática procura valorizar os diferentes modos de pensamento e raciocínio matemático que foram desenvolvidos pelos membros de diferentes culturas para promover as estratégias e as técnicas necessárias para explicar os procedimentos utilizados para a resolução e a compreensão dos diferentes acontecimentos e fenômenos presentes em situações cotidianas (ROSA; OREY, 2006).

Nesse contexto, o "mundo constrói-se em um processo cognitivo epistemologicamente transacional, através das interações sujeito/palavra/objeto" (VERGANI, 2007, p. 29) com o ambiente no qual os alunos estão inseridos. 


\section{Dimensão epistemológica}

No Programa Etnomatemática, os sistemas de conhecimentos são percebidos como conjuntos de respostas que os membros de grupos culturais distintos determinam para entender os pulsões de sobrevivência e transcendência que têm relação com os fazeres e saberes que são inerentes e intrínsecos à espécie humana (D’AMBROSIO, 2009).

Esses fazeres podem ser considerados como as observações provenientes da realidade, que são denominadas como conhecimentos empíricos enquanto os saberes são considerados como um conjunto de princípios fundamentais de uma ciência, que são denominados de conhecimentos teóricos. Então, um dos principais objetivos do Programa Etnomatemática é entender a relação entre os fazeres e os saberes de uma determinada cultura (ROSA; OREY, 2015).

Para que possamos entender o relacionamento entre os fazeres (observação da realidade por meio do empirismo) e os saberes (concepções teóricas para a compreensão e explicação da realidade), D’Ambrosio (2009) comenta sobre três questões que servem de base para explicar a evolução do conhecimento humano: 1) Como passamos de observações e práticas ad hoc ${ }^{3}$ para experimentação e método?, 2) Como passamos de experimentação e método para reflexão e abstração? e 3) Como procedemos para invenções e teorias?

\section{Dimensão política}

Históricamente, a matemática tem se tornado um filtro social e, a partir da expansão marítima dos séculos XV e XVI, essa disciplina está

\footnotetext{
${ }^{3} A d$ hoc é uma expressão latina, cujo significado está relacionado com a determinação de uma solução específica para a resolução de um determinado problema ou situação, que não é generalizada e nem adaptada para outros propósitos. Nesse caso, essas observações e práticas são específicas e únicas, pois não são adequadas para a realização de generalizações.
} 
"associada a um processo de dominação e à estrutura de poder desse processo" (D’AMBROSIO, 1998, p. 14).

Com o período da colonização, a matemática transformou-se em "um instrumento selecionador de elites" (D'AMBROSIO, 2009, p. 77). Ressalta-se que, durante qualquer processo de colonização, os dominadores proíbem a manifestação dos dominados. Então, para atingir esse objetivo, os dominadores utilizam a sua principal estratégia que é manter os dominados inferiorizados (ALVES, 2014).

Convém salientar que nas escolas ocorre um processo análogo, pois o sistema educacional foi ampliado para acolher também as crianças e os jovens das classes minoritárias com a promessa de que conseguiriam o acesso social. No entanto, os "resultados negativos e perversos [desse processo] se manifestam, sobretudo, no exercício de poder e na eliminação ou exclusão dos dominados" (D’AMBROSIO, 2009, p. 41).

Assim, nessa dimensão, o Programa Etnomatemática procura reestruturar e fortalecer as raízes culturais dos indivíduos pertencentes às minorias e às classes dominadas, pois visa valorizar e respeitar a história, a tradição e o pensamento matemático dos membros desses grupos culturais.

Adicionalmente, Rosa (2010) argumenta que o Programa Etnomatemática também reconhece, respeita e valoriza a tradição e o pensamento matemático desenvolvido pelos membros de outros grupos culturais, auxiliando-os a reforçarem as próprias raízes, bem como promover o dinamismo cultural.

\section{Dimensão educacional}

A “proposta pedagógica da Etnomatemática é fazer da Matemática algo vivo, lidando com situações reais no tempo [agora] e no espaço [aqui] e, através da crítica, questionar o aqui e agora" (D'AMBROSIO, 2009, p. 46).

Contudo, talvez, o "maior desafio conceitual na educação [matemática] seja passar do linear para o complexo e do quantitativo para o qualitativo" 
(D’AMBROSIO, 2003, p. 7) na elaboração das atividades curriculares propostas em uma perspectiva da Etnomatemática.

Então, é essencial incorporar os aspectos culturais do conhecimento matemático nas atividades curriculares que visa promover o caráter qualitativo para os seus conteúdos para que os alunos possam percebê-la como uma ciência humana (ROSA; OREY, 2015).

Contudo, para que a ação pedagógica do Programa Etnomatemática seja eficaz, existe a necessidade da incorporação dos aspectos culturais da matemática e da contextualização de seus conteúdos (D’AMBROSIO, 2009) no currículo escolar.

De acordo com essa ação pedagógica, é importante reconhecer que os alunos possuem conhecimentos etnomatemáticos, denominados de etnoconhecimento (BORBA, 1990), que são adquiridos nos ambientes social, cultural, político, ambiental e econômico nos quais esse corpo docente está inserido.

Nesse direcionamento, Rosa (2010) argumenta que a Etnomatemática como um Programa traz uma proposta pedagógica e educacional que considera a matemática como uma ciência viva e humana, que trabalha com situações reais de espaço (aqui) e tempo (agora).

\section{Dimensão conceitual}

Os desafios impostos pela vida cotidiana possibilitam que os membros de grupos culturais distintos elaborem teorias, métodos e práticas a partir de representações da realidade com o objetivo de resolverem as questões existenciais e comportamentais (D'AMBROSIO, 2009).

Por exemplo, Rosa (2010) argumenta que essas teorias, métodos e práticas compõem uma base fundamental para o desenvolvimento de conhecimentos matemáticos, bem como para a tomada de decisões necessária a resolução de situações-problema enfrentadas no cotidiano. Esses conhecimentos são fundamentais para a o desenvolvimento da 
elaboração de representação da realidade e, consequentemente, para a criação de modelos que respondam à percepção de espaço (aqui) e de tempo (agora).

Dessa maneira, o conhecimento se desenvolve por meio da utilização e da análise das experiências vivenciadas, pois é elaborado com referência na realidade e sobre o comportamento dos indivíduos de acordo com as normas aceitas pelos membros de uma determinada cultura (D'AMBROSIO, 1998). Esse novo conhecimento é processado conforme a percepção da realidade de cada um desses membros, que processa a nova informação conforme os seus mecanismos genéticos, sensoriais e de memória (ALVES, 2014).

Nesse processo, os membros desses grupos culturais acrescentam à sua realidade os artefatos que são elaborados por meio das representações, das tecnologias e das expressões materiais que estão relacionadas com a própria experiência material, que também incorpora os mentefatos que são as ideias, os valores, as crenças e a simbologia, que estão relacionadas com o desenvolvimento do pensamento abstrato.

\section{Procedimentos metodológicos}

Essa investigação, de caráter bibliográfico, possui características de um estudo do tipo estado da arte, que tem como objetivo favorecer a consolidação, a valorização e o fortalecimento de um determinado campo de pesquisa, pois busca identificar as principais temáticas abordadas e as suas perspectivas, convergências e distanciamentos (FERREIRA, 2002).

Assim, essa investigação buscou mapear e discutir a produção científica em Etnomatemática para verificar quais dimensões foram destacadas e privilegiadas nos anais de congressos brasileiros relacionados com esse Programa. De acordo com Romanowski e Ens (2006) citado por Nogueira Martins e Farias Gonçalves (2015), as investigações desse tipo: 
(...) caracterizam-se por apresentar contribuições na constituição do campo teórico de diferentes áreas do conhecimento, uma vez que busca identificar os aportes significativos da construção da teoria e prática pedagógica, apontar as restrições sobre um campo em que se move a pesquisa, as suas lacunas de disseminação, abordar experiências inovadoras investigadas que apontem alternativas de solução para os problemas da prática e reconhecer os subsídios da pesquisa na constituição de propostas na área focalizada (p. 112).

Os congressos brasileiros de Etnomatemática foram selecionados para a elaboração desse estado de arte por ser o mais importante congresso nacional em Etnomatemática. Dessa maneira, restringimos a análise da produção científica desse Programa no estudo dos anais das cinco edições desse congresso, realizadas no período de 2000 a 2016.

Definida as publicações a serem analisadas (conferências, mesas redondas, fóruns, pôsteres, oficinas, minicursos, comunicações e relatos de experiência) realizou-se uma leitura dos resumos dos 463 trabalhos acadêmicos que foram apresentados e publicados nos anais desses congressos.

\section{Estado da arte nos cinco congressos brasileiros de Etnomatemática}

Para que se possa entender o desenvolvimento do Programa Etnomatemática, existe a necessidade de discutirmos a sua produção científica para analisarmos os seus objetivos e as suas premissas em relação à ética, ao respeito, à solidariedade, à interação, à cooperação e à colaboração entre os membros de culturas distintas. Então, o estado da arte em Etnomatemática pode endereçar os temas relacionados com a sua ação pedagógica na Educação Matemática, bem como a sua relação com as seis dimensões desse Programa. 
O foco desse estado da arte são os trabalhos acadêmicos produzidos no Brasil, no periodo de 2000 a 2016, com relação aos cinco congressos brasileiros de Etnomatemática realizados em São Paulo, SP (2000), Natal, RN (2004), Niterói, RJ (2008), Belém (PA) 2012 e Goiânia (2016). Esses trabalhos foram analisados e categorizados de acordo com as seis dimensões do Programa Etnomatemática conforme os procedimentos metodológicos utilizados por Alangui e Rosa (2016).

Por exemplo, os quadros de 1 a 5 mostram os resultados dos trabalhos acadêmicos analisados em cada CBEm nos cinco congressos realizados período de 2000 a 2016 .

QUADRO 1: CBEm1 - São Paulo, SP (USP)

\begin{tabular}{|l|c|c|c|c|c|c|c|}
\hline Dimensões/Atividade & Conferências & $\begin{array}{c}\text { M esas } \\
\text { Redondas }\end{array}$ & Fóruns & Pôsteres & $\begin{array}{c}\text { Oficinas/ } \\
\text { Minicursos }\end{array}$ & $\begin{array}{c}\text { Comunicações/ } \\
\text { Relatos }\end{array}$ & T otal \\
\hline E pistemológica & 3 & 1 & 1 & & & 10 & 15 \\
Histórica & 2 & 3 & 1 & & & 6 & 7 \\
E ducacional & 1 & & & & & 19 & 25 \\
Política & 2 & & & & & 1 & 1 \\
Cognitiva & 8 & 4 & 3 & & & 9 & 9 \\
Conceitual & & & 1 & & 53 & 68 \\
\hline T otal & & & & & & 11 \\
\hline
\end{tabular}

Fonte: Arquivo pessoal dos autores

QUADRO 2: CBEm2 - Natal, RN (UFRN)

\begin{tabular}{|c|c|c|c|c|c|c|c|}
\hline Dimensões/Atividade & Conferências & \begin{tabular}{|c|} 
M esas \\
Redondas
\end{tabular} & Fóruns & Pôsteres & \begin{tabular}{|c|} 
Oficinas/ \\
Minicursos
\end{tabular} & $\begin{array}{c}\text { Comunicaçõos/ } \\
\text { Relatos }\end{array}$ & Total \\
\hline E pistemológica & & 1 & & 2 & 2 & 5 & 10 \\
\hline Histórica & & & & 1 & & 4 & 5 \\
\hline E ducacional & & 2 & & 3 & 2 & 8 & 15 \\
\hline Política & 1 & 1 & & 1 & & 1 & 4 \\
\hline Cognitiva & & 1 & & 3 & 1 & 4 & 9 \\
\hline Conceitual & & & & & 2 & 6 & 8 \\
\hline T otal & 1 & 5 & & 10 & 7 & 28 & 51 \\
\hline
\end{tabular}


QUADRO 3: CBEm34 - Niterói, RJ (UFF)

\begin{tabular}{|c|c|c|c|c|c|c|c|}
\hline Dimensões/Ativid ade & Conferências & \begin{tabular}{|c|} 
Mesas \\
Redondas
\end{tabular} & Fóruns & Pôsteres & \begin{tabular}{|c|} 
Oficinas/ \\
Minicursos
\end{tabular} & \begin{tabular}{|c|}
$\begin{array}{c}\text { Comunicações/ } \\
\text { Relatos }\end{array}$ \\
\end{tabular} & T otal \\
\hline E pistemológica & 3 & 2 & & 3 & & 11 & 19 \\
\hline Histórica & 1 & & & & & 3 & 4 \\
\hline Educacional & & 2 & & 9 & 3 & 24 & 38 \\
\hline Política & & & & & & 2 & 2 \\
\hline Cognitiva & & & & 4 & 1 & 12 & 17 \\
\hline Conceitual & & 1 & & 3 & 1 & 10 & 15 \\
\hline Total & 4 & 5 & & 19 & 5 & 62 & 95 \\
\hline
\end{tabular}

QUADRO 4: CBEm4 - Belém, PA (UFPA)

\begin{tabular}{|c|c|c|c|c|c|c|c|}
\hline Dimensões/Atividade & Conferências & \begin{tabular}{|c|} 
Mesas \\
Redondas as
\end{tabular} & Fóruns & Pôsteres & \begin{tabular}{|c|} 
Oficinas/ \\
Minicursos \\
\end{tabular} & \begin{tabular}{|c}
$\begin{array}{c}\text { Comunicações/ } \\
\text { Relatos }\end{array}$ \\
\end{tabular} & Total \\
\hline E pistemológica & 1 & 1 & & 3 & & 11 & 16 \\
\hline $\begin{array}{l}\text { Histórica } \\
\text { F ducarional }\end{array}$ & 1 & & & 2 & & 2 & $\begin{array}{c}4 \\
58\end{array}$ \\
\hline $\begin{array}{l}\text { E ducacional } \\
\text { Política }\end{array}$ & 1 & 1 & & $\begin{array}{c}18 \\
1\end{array}$ & & $\begin{array}{c}38 \\
6\end{array}$ & $\begin{array}{r}58 \\
7\end{array}$ \\
\hline Cognitiva & & & & 5 & & 17 & 22 \\
\hline Conceitual & 1 & 1 & & 3 & & 8 & 13 \\
\hline T otal & 3 & 3 & & 32 & & 82 & 120 \\
\hline
\end{tabular}

Fonte: Arquivo pessoal dos autores

QUADRO 5: CBEm5 - Goiânia, GO (UFG)

\begin{tabular}{|c|c|c|c|c|c|c|c|}
\hline Dimensões/Atividade & Conferências & $\begin{array}{c}\text { Mesas } \\
\text { Redond as }\end{array}$ & Fóruns & Pôsteres & \begin{tabular}{|c|} 
Oficinas/ \\
Minicursos
\end{tabular} & $\begin{array}{c}\text { Comunicações/ } \\
\text { Relatos }\end{array}$ & T otal \\
\hline $\begin{array}{l}\text { E pistemológica } \\
\text { Histórica }\end{array}$ & 1 & 1 & & 3 & \begin{tabular}{|c|}
3 \\
\end{tabular} & \begin{tabular}{|c|}
15 \\
6
\end{tabular} & $\begin{array}{r}23 \\
7\end{array}$ \\
\hline E ducacional & & & & 4 & 8 & 30 & 42 \\
\hline Política & & & & & 1 & 8 & 9 \\
\hline Cognitiva & & & & 5 & 3 & 19 & 27 \\
\hline Conceitual & & 1 & & 3 & 3 & 14 & 21 \\
\hline T otal & 1 & 3 & & 15 & 18 & 92 & 129 \\
\hline
\end{tabular}

Fonte: Arquivo pessoal dos autores

O quadro 6 mostra a totalização dos trabalhos analisados nos cinco congressos brasileiros de Etnomatemática no período de 2000 a 2016 enquanto o quatro 7 mostra esse resultado final em porcentagem.

\footnotetext{
${ }^{4}$ Nesses fóruns, os participantes, mediados por pesquisadores mais experientes, tinham um tempo reservado para debater as questões discutidas nos diferentes espaços do congresso. Essa dinâmica possibilitou que houvesse um aprofundamento dos debates e uma relação menos vertical entre os participantes e os conferencistas (FANTINATO, 2013).
} 
QUADRO 6: Totalização dos cinco congressos brasileiros de Etnomatemática (CBEm)

\begin{tabular}{|l|c|c|c|c|c|c|c|}
\hline Dimensões/Ativid ade & Conferências & $\begin{array}{c}\text { M esas } \\
\text { Redondas }\end{array}$ & Fóruns & Pôsteres & $\begin{array}{c}\text { Oficinas/ } \\
\text { Minicursos }\end{array}$ & $\begin{array}{c}\text { Comunicações/ } \\
\text { Relatos }\end{array}$ & Total \\
\hline E pistemológica & 8 & 6 & 1 & 11 & 5 & 52 & 83 \\
Histórica & 1 & 1 & 1 & 3 & & 21 & 27 \\
E ducacional & 3 & 8 & 1 & 34 & 13 & 119 & 178 \\
Política & 1 & 1 & & 2 & 1 & 18 & 23 \\
Cognitiva & 1 & 1 & & 17 & 5 & 60 & 84 \\
Conceitual & 3 & 3 & & 9 & 6 & 47 & 68 \\
\hline Total & 17 & 20 & 3 & 76 & 30 & 317 & 463 \\
\hline
\end{tabular}

Fonte: Arquivo pessoal dos autores

QUADRO 7: Resultado final, em porcentagem, referente aos CBEm

\begin{tabular}{|l|c|c|}
\hline \multicolumn{1}{|c|}{ Dimensões } & Frequência & Porcentagem (\%) \\
\hline E pistemológica & 83 & $17,9 \%$ \\
Histórica & 27 & $5,8 \%$ \\
E ducacional & 178 & $38,5 \%$ \\
Política & 23 & $5,0 \%$ \\
Cognitiva & 84 & $18,1 \%$ \\
Conceitual & 68 & $14,7 \%$ \\
\hline Total & 463 & $100,0 \%$ \\
\hline
\end{tabular}

Fonte: Arquivo pessoal dos autores

Essa pesquisa sobre o estado da arte dos congressos brasileiros de Etnomatemática endereçou temáticas relacionadas com as seis dimensões desse Programa. Por exemplo, a análise dos dados nas tabelas mostra que a Educação é a dimensão com a maior produção acadêmica nesses congressos, demonstrando a sua importância para a Educação Matemática. Por outro lado, a análise desses dados também mostra que as dimensões política e histórica da Etnomatemática tiveram, respectivamente, uma menor produção acadêmica nesses congressos.

Por exemplo, a totalização da producão referente à dimensão educacional representou $36,3 \%$ dos trabalhos apresentados nesses congressos enquanto a produção das dimensões histórica e política totalizou $5,8 \%$ e $5,0 \%$, respectivamente.

Essa conclusão é semelhante aos resultados obtidos pelo estudo conduzido por Fantinato (2013) que mostram uma preocupação dos pesquisadores e educadores com a dimensão educacional da Etnomatemática ao enfatizar a educação matemática no espaço escolar 
enquanto argumenta que a produção referente à dimensão histórica tem sido pouco expressiva nos congressos brasileiros de Etnomatemática. Essa pesquisadora também concluiu que, de acordo com essa abordagem, existe a necessidade da continuidade de investigações nessas dimensões.

Resultados similares também foram obtidos no estado da arte desenvolvido por Alangui e Rosa (2016) com referência à produção acadêmica internacional em Etnomatemática, considerando as investigações brasileiras de mestrado e doutorado no período de 2005 a 2016, bem como os trabalhos científicos apresentados nos Congressos Internacionais de Etnomatemática da Nova Zelândia (2006), Estados Unidos (2010) e Moçambique (2014).

Nessa pesquisa internacional foram estudados os resumos de 150 investigações de mestrado e doutorado defendidos no Brasil e 123 trabalhos apresentados nos três últimos congressos de Etnomatemática, totalizando 273 trabalhos analisados. As conclusões resultantes dessa pesquisa internacional mostram que foram encontrados resultados parecidos aos determinados nos CBEm, demonstrando que a ação pedagógica do Programa Etnomatemática é também uma preocupação internacional, bem como a reduzida quantidade de trabalhos dedicados às dimensões história e política desse Programa (quadro 8).

QUADRO 8: Resultado final em porcentagem referente ao estado da arte internacional em Etnomatemática

\begin{tabular}{|l|c|c|}
\hline \multicolumn{1}{|c|}{ Dimensões } & Frequência & Porcentagem (\%) \\
\hline E pistemológica & 34 & $12,5 \%$ \\
Histórica & 24 & $8,7 \%$ \\
Educacional & 99 & $36,4 \%$ \\
Política & 24 & $8,7 \%$ \\
Cognitiva & 38 & $13,9 \%$ \\
Conceitual & 54 & $19,8 \%$ \\
\hline Total & 273 & $100,0 \%$ \\
\hline
\end{tabular}

Fonte: Adaptado de Alangui e Rosa (2016)

Esse estudo do estado da arte mostra que é necessário inserir questões relacionadas com a utilização do conhecimento matemático desenvolvido 
pelos membros de grupos culturais distintos através de suas conexões com as ações pedagógicas propostas pelo Programa Etnomatemática.

No entanto, as discussões sobre essas questões não implicam, necessariamente, que a Etnomatemática possa ser considerada apenas um instrumento utilizado para possibilitar o desenvolvimento da Educação Matemática, pois esse Programa também assume papéis importantes para propiciar esclarecimentos sobre a natureza do conhecimento matemático.

Assim, buscamos apresentar de maneira sucinta alguns aspectos que podem ser relevantes para os objetivos que podem ser alcançados com a utilização da ação pedagógica do Programa Etnomatemática em sala de aula.

Nesse direcionamento, é necessário que os investigadores e educadores se conscientizem sobre o estabelecimento de relações entre a matemática acadêmica e o conhecimento matemático adquirido informalmente pelos alunos em seus próprios contextos para auxiliá-los na percepção da presença humanizada da matemática nas atividades e tarefas realizadas diariamente (ROSA; OREY, 2006).

Desse modo, a dimensão educacional do Programa Etnomatemática identificada nesse estado da arte mostra que o processo de ensino e aprendizagem em matemática deve considerar o conhecimento matemático originado e construído nas práticas culturais da comunidade como um instrumento educacional utilizado para que os alunos possam alcançar os objetivos propostos pela educação.

Essa perspectiva possibilita a caracterização de ações pedagógicas desenvolvidas por meio de atividades contextualizadas, que são originadas no contexto sociocultural dos alunos. Então, de acordo om Rosa e Orey (2006), é possível a exploração das ideias, procedimentos e práticas matemáticas locais, respeitando os valores culturais das comunidades e os conhecimentos adquiridos através da vivência em sociedade.

Por conseguinte, esse estado da arte mostrou que a ação pedagógica do Programa Etnomatemática por meio de sua dimensão educacional está 
relacionada com a: educação rural e do campo, educação indígena, educação urbana, educação de jovens e adultos, educação ambiental, educação inclusiva, educação matemática em diferentes contextos culturais e a formação de professores. Por exemplo, a dimensão educacional da Etnomatemática tem como objetivo verificar as contribuições e as potencialidades pedagógicas que esse Programa pode oferecer para o desenvolvimento dos alunos em sala de aula.

Além disso, a análise desse estado da arte mostra que em todas em as pesquisas relatadas, os resultados apontaram para um despertar crítico e reflexivo dos professores e alunos para o conhecimento matemático presente nas práticas cotidianas que podem ser desenvolvidas em salas de aula.

Nessa ação pedagógica, D'Ambrosio e Rosa (2008) afirmam que os alunos devem ser orientados a criarem o conhecimento matemático por meio da problematização de situações vivenciadas no cotidiano, oportunizando o desenvolvimento de habilidades e competências, cujos objetivos estão além do aprendizado do conteúdo matemático estabelecido nos programas curriculares.

Então, o conhecimento etnomatemático pode ser utilizado por meio da observação, interpretação ou descrição de uma ação que originou uma prática matemática necessária para resolver uma situação-problema enfrentada pelos membros de grupos culturais distintos em seu cotidiano (ROSA, OREY, 2006).

Desse modo, para D’Ambrosio (1998), o Programa Etnomatemática visa a organização intelectual e social do conhecimento matemático, cuja difusão ocorre a partir das relações interculturais que se manifestam no decorrer da história em diversos contextos socioculturais.

Consequentemente, concebemos a Etnomatemática como uma forma de linguagem desenvolvida para que os membros de grupos culturais distintos possam comunicar, descrever, mediar, traduzir e modelar um determinado fenômeno que enfrentam em seu próprio cotidiano. 


\section{Considerações Finais}

Com o crescimento linguístico e étnico da população estudantil nas escolas, é importante que o currículo escolar seja um reflexo da aprendizagem sociocultural dos alunos e que os professores sejam apoiados em sua preparação para endereçar essas diferenças.

Assim, a etnomatematica utiliza as experiências socioculturais e as práticas matemáticas dos alunos que são desenvolvidas em suas comunidades para utilizaá-las como veículos que podem tornar a aprendizagem matemática relevante, fornecendo informações sobre 0 conhecimento matemático incorporado em diversos contextos.

Então, é necessário que os professores enfatizem as conexões entre a matemática e outras disciplinas curriculares, bem como considerem os antecedentes culturais dos alunos na concepção, seleção, elaboração e organização das atividades escolares.

Essa abordagem, de acordo com Rosa (2010), propicia o desenvolvimento da aprendizagem em matemática meio da utilização de abordagens sociais e afetivas, da harmonia com a comunidade, das perspectivas holísticas do conhecimento, da criatividade e da comunicação não verbal. Esse contexto possibilita a evolução da Etnomatemática como um campo de pesquisa que busca vincular o conhecimento local ao currículo matemático com a aplicação de abordagens pedagógicas inovadoras.

Contudo, para que possamos perceber a conexão entre a cultura e a matemática, é necessário ressaltarmos a importância de se fazer, primeiramente, o trabalho etnomatemático por meio de uma compreensão relevante dos aspectos matemáticos da cultura, que tem como objetivo o desenvolvimento de sua atividade pedagógica, ilustrando como as ideias, os procedimentos e as práticas matemáticas desempenham um papel vital na evolução dos esforços humanos para a valorização das diferenças. Assim, a etnomatematica constitui uma base teórica para as contribuições 
significativas para repensar e reconceituar a natureza do conhecimento matemático.

Essa dimensão educacional é essencial para o desenvolvimento da ação pedagógica do Programa Etnomatemática que tem como um de seus objetivos a investigação do conhecimento matemático local. Então, é importatne ampliar a discussão sobre as possibilidades de inclusão de perspectivas Etnomatemáticas nos espaços escolares, que respeitem e deem voz para a diversidade sociocultural dos membros de grupos culturais distintos com garantias para o desenvolvimento da compreensão das diferenças através do diálogo e respeito.

Finalizando, em nosso ponto de vista, esse artigo pode propiciar o debate de algumas ideias importantes que podem proporcionar uma compreensão abrangente da Etnomatemática e de seu estado da arte com relação aos congressos brasileiros por meio da discussão de suas ações pedagógicas, de suas contribuições para a formação de professores e de seu papel na Educação Matemática, de acordo com a análise das seis dimensões desse Programa.

Desse modo, o estado de arte apresentado nesse artigo evidencia que a utilização do Programa Etnomatemática em sala de aula, como uma ação pedagógica, pode auxiliar os alunos na valorização dos conhecimentos oriundos de suas experiências culturais para que sejam compartilhados no ambiente escolar com o objetivo de auxiliá-los na aprendizagem em matemática por meio de sua dimensão educacional.

Por conseguinte, esperamos que esse estado da arte sobre os cinco congressos brasileiros de Etnomatemática possa estimular a discussão e encorajar a condução de estudos e investigações relacionadas com as seis dimensões desse Programa. 


\section{Referências}

ALANGUI, W. V.; ROSA, M. Role of ethnomathematics in mathematics education. In ROSA, M.; D'AMBROSIO, U., OREY, D. C., SHIRLEY, L., ALANGUI, W. V., PALHARES, P.; GAVARRETE, M. A. (Eds.). Current and future perspectives of ethnomathematics as a program. Cham, Switzerland: SpringerOpen, 2016. pp. 3137.

ALVES, G. M. As contribuições da Etnomatemática e da perspectiva sociocultural da história da matemática para a formação da cidadania dos alunos de uma turma do 8. ${ }^{\circ}$ ano do ensino fundamental por meio do ensino e aprendizagem de conteúdos da educação financeira. Dissertação (Mestrado). Departamento de Matemática. Ouro Preto, MG: UFOP, 2014.

BORBA, M. C. Ethnomathematics and education. For the Learning of Mathematics, v. 10, n. 1, p. 39-43, 1990.

D'AMBROSIO, U. Etnomatemática: arte ou técnica de explicar e conhecer. São Paulo, SP: Editora Ática, 1998.

História, Etnomatemática, educação e modelagem. XI CIAEM - Blumenau, SC: FURB, 2003.

Etnomatemática: elo entre as tradições e a modernidade. Belo Horizonte, MG: Autêntica, 2009.

D'AMBROSIO, U.; ROSA, M. Um diálogo com Ubiratan D'Ambrosio: uma conversa brasileira sobre Etnomatemática. Revista Latinoamericana de Etnomatemática, v. 1, n. 2, p. 88-110, 2008.

FANTINATO, M. C. Balanço da produção acadêmica dos congressos brasileiros de Etnomatemática. Unión - Revista Iberoamericana de Educación Matemática, n. 33, p. 147-161, 2013.

FERREIRA, N. S. A. As pesquisas denominadas 'Estado da Arte'. Revista Educação \& Sociedade, v. 23, n. 79, p. 257-272, 2002.

MOREY, B. B. Anais do II Congresso Brasileiro de Etnomatemática - CBEm2. Natal, RN: UFRN, 2004.

NOGUEIRA MARTINS, F.; FARIAS GONÇALVES, P. G. Pesquisas em Etnomatemática e suas contribuições para o contexto escolar: um olhar para os anais dos CBEm. Revista Latinoamericana de Etnomatemática, v. 8, n. 1, p. 108$123,2015$.

ROSA, M. A mixed-methods study to understand the perceptions of high school leaders about English Language Learners (ELL) students: the case of mathematics. Tese de Doutorado. College of Education. Sacramento, CA: California State University, Sacramento - CSUS, 2010. 
ROSA, M.; OREY, D. C. Abordagens atuais do Programa Etnomatemática: delineando-se um caminho para a ação pedagógica. BOLEMA, v. 19, n. 26, p. 19 48, 2006.

. Evidence of creative insubordination in the research of pedagogical action of ethnomathematics program. In D'AMBROSIO, B. S.; LOPES, C. E (Orgs.). Creative insubordination in Brazilian mathematics education research. Raleigh: Lulu Press, 2015. pp. 131-146.

VERGANI, T. Educação Etnomatemática: o que é. Natal, RN: Flecha do Tempo, 2007.

Recebido em junho de 2018.

Aprovado em outubro de 2018. 